\title{
Biocompatible Metal-Oxide Nanoparticles: Nanotechnology Improvement of Conventional Prosthetic Acrylic Resins
}

\author{
Laura S. Acosta-Torres, ${ }^{1}$ Luz M. López-Marín, ${ }^{1}$ R. Elvira Núñez-Anita, ${ }^{2}$ \\ Genoveva Hernández-Padrón, ${ }^{1}$ and Victor M. Castaño ${ }^{1}$ \\ ${ }^{1}$ Centro de Física Aplicada y Tecnología Avanzada, Universidad Nacional Autónoma de México, Boulevard Juriquilla 3001, \\ Santiago de Querétaro, Querétaro 76230, Mexico \\ ${ }^{2}$ Instituto de Neurobiología, Universidad Nacional Autónoma de México, Boulevard Juriquilla 3001, \\ Santiago de Querétaro, Querétaro 76230, Mexico \\ Correspondence should be addressed to Victor M. Castaño, castano@fata.unam.mx
}

Received 28 April 2010; Revised 30 June 2010; Accepted 6 September 2010

Academic Editor: Libo Wu

Copyright () 2011 Laura S. Acosta-Torres et al. This is an open access article distributed under the Creative Commons Attribution License, which permits unrestricted use, distribution, and reproduction in any medium, provided the original work is properly cited.

\begin{abstract}
Nowadays, most products for dental restoration are produced from acrylic resins based on heat-cured Poly(Methyl MethAcrylate) (PMMA). The addition of metal nanoparticles to organic materials is known to increase the surface hydrophobicity and to reduce adherence to biomolecules. This paper describes the use of nanostructured materials, $\mathrm{TiO}_{2}$ and $\mathrm{Fe}_{2} \mathrm{O}_{3}$, for simultaneously coloring and/or improving the antimicrobial properties of PMMA resins. Nanoparticles of metal oxides were included during suspension polymerization to produce hybrid metal oxides-alginate-containing PMMA. Metal oxide nanoparticles were characterized by dynamic light scattering, and X-ray diffraction. Physicochemical characterization of synthesized resins was assessed by a combination of spectroscopy, scanning electron microscopy, viscometry, porosity, and mechanical tests. Adherence of Candida albicans cells and cellular compatibility assays were performed to explore biocompatibility and microbial adhesion of standard and novel materials. Our results show that introduction of biocompatible metal nanoparticles is a suitable means for the improvement of conventional acrylic dental resins.
\end{abstract}

\section{Introduction}

To date, up to $95 \%$ dental prostheses are composed of Poly(Methyl MethAcrylate) (PMMA), due to its advantages, including its optical properties, biocompatibility, and aesthetics $[1,2]$. However, important issues are still to be addressed in order to improve acrylic polymers properties for artificial dentures. For instance, microbial adhesion onto PMMA has been a long-standing drawback accompanying long-term PMMA wearers. In dentistry, adhesion and plaque formation onto PMMA-based resins is a common source of oral cavity infections and stomatitis [3]. These affections may cmtinvolve a variety of human pathogens and have been commonly associated to the oral commensal Candida albicans [4], an opportunistic pathogen causing emergent disease within immune suppressed patients [5]. Microbial adhesion has also been a limiting factor for other PMMA biomedical applications, such as ophthalmic prostheses, contact lenses and bone repair $[6,7]$. Other weak points of PMMA materials include lack of strength and toxicity [8]. Therefore, the search for innovative solutions addressing these problems is of special interest in the development of acrylic materials-based implants.

Dental prostheses may include titanium oxide $\left(\mathrm{TiO}_{2}\right)$ as a coloring agent; hybrid materials ranging from yellowedtransparent to red colors may be obtained using $\mathrm{TiO}_{2}$ into a given PMMA formulation. Interestingly, nanosized structured $\mathrm{TiO}_{2}$ has proved to bear antimicrobial properties, due to $\mathrm{TiO}_{2}$-induced photocatalytic production of cytotoxic oxygen radicals [9]. In 1985, Matsunaga et al. reported for the first time the microbicidal effect of $\mathrm{TiO}_{2}$ photocatalytic reaction [10]. $\mathrm{TiO}_{2}$ exhibits strong oxidizing power under irradiation of UV light with water and oxygen environment around $\mathrm{TiO}_{2}$. Consequently, irradiated $\mathrm{TiO}_{2}$ can decompose 
and/or oxidize most of organic and/or inorganic compounds [11]. This phenomenon may increase the applicability of titania for use in the destruction of microorganisms, which consist primarily of organic-based compounds. In addition, its high chemical stability, low cost, and nontoxicity make $\mathrm{TiO}_{2}$ ideal as an alternative material for improving antimicrobial properties. Up to now, antibacterial applications of $\mathrm{TiO}_{2}$ have been employed in various environmental settings.

Various studies have shown that doping $\mathrm{TiO}_{2}$ with metal or metal oxides, such as $\mathrm{Fe}^{3+}$, strongly improve the photocatalytic activity, hence increasing their disinfection effect $[10,11]$. In the present study, both $\mathrm{TiO}_{2}$ and $\mathrm{Fe}_{2} \mathrm{O}_{3}$ nanoparticles have been integrated into alginate-containing PMMA resins designed as "pink" gingival substitute and artificial dental holders. Hybrid inorganic-PMMA materials were prepared by introducing $\mathrm{TiO}_{2}$ and $\mathrm{Fe}_{2} \mathrm{O}_{3}$ nanoparticles during acrylate synthesis. A combination of physicochemical, microscopy, and biological analyses were used to characterize the novel nanoparticles-containing acrylic formulation.

\section{Materials and Methods}

2.1. Nanoparticles and Reagents. $\mathrm{TiO}_{2}$ and $\mathrm{Fe}_{2} \mathrm{O}_{3}$ were kindly supplied by González Cano y Compañía (Mexico). Methyl Methacrylate, Peroxide Benzoyl and Toluene were purchased from Sigma (St. Louis, MO), and Sodium Alginate was obtained from Manufacturera Dental Continental (Mexico).

2.2. PMMA Synthesis. Standard PMMA was synthesized when Methyl MethAcrylate (MMA) monomer (200 g) was dispersed in $800 \mathrm{~mL}$ of deionized water in a five-neck glass reactor under nitrogen atmosphere at $70 \pm 1^{\circ} \mathrm{C}$ and $1200 \mathrm{rpm}$ under reflux. Then, the suspension was mixed with sodium alginate $(2.5 \%)$ as suspension agent and peroxide benzoyl as initiator $(1 \%)$. For the nanopigmented PMMA formulation, $\mathrm{TiO}_{2}(0.0150 \mathrm{~g})$ and $\mathrm{Fe}_{2} \mathrm{O}_{3}(0.009 \mathrm{~g})$ were dissolved in water and incorporated with MMA to the reaction system. The resulting PMMA particles were carefully washed and dried at $60^{\circ} \mathrm{C}$ during $24 \mathrm{~h}$. Specimens were prepared by mixing PMMA powder with MMA $(3: 1)$ and $1 \%$ initiator and packed into molds. Then, thermopolymerization was conducted in a water bath at $70 \pm 1^{\circ} \mathrm{C}$ during $90 \mathrm{~min}$ followed by $30 \mathrm{~min}$ in boiling water. Specimens were trimmed with wet abrasive paper of grit 100 and 300 (Fandeli, Mexico), in order to obtain $65 \times 10 \times 2.5 \mathrm{~mm}$ samples for flexural behavior analyses, $30 \times 10 \times 2.5 \mathrm{~mm}$ for porosity test, $10 \times 0.5 \mathrm{~mm}$ discs for water sorption and solubility tests, and $10 \times 2 \mathrm{~mm}$ discs for toxicity assay and Candida albicans adhesion test. The upper and lower planes of discs for biological assays were untouched.

2.3. Dynamic Light Scattering. Prior to use, all the solvents used were filtrated with $0.2 \mu \mathrm{m}$ filters to eliminate dust and the sample holder was cleaned with distilled water followed by acetone, to prevent contamination. For each sample, $2 \mathrm{mg}$ of particles were suspended in $20 \mathrm{~mL}$ of solvent and filtrated. The samples were maintained in an ultrasonic bath for $10 \mathrm{~min}$. The scattering cells $(10-\mathrm{mL}$ cylindrical vials) were immersed in a large-diameter thermostated bath of indexmatching liquid (transdecalin). Dynamic Light Scattering (DLS) measurements were performed in a B1-200SM instrument (Brookhaven Instruments Co., Holstsville, NY). The results were analyzed by using the Nonnegative Least Square (NNLS) and Contin methods.

2.4. X-Ray Diffraction (XRD). XRD was used to determine the phases present in the $\mathrm{TiO}_{2}$ and $\mathrm{Fe}_{2} \mathrm{O}_{3}$ particles. Diffractograms were recorded on a MiniFlex, Rigaku Diffractometer. A $2 \theta$ diffraction angle per min ranging from $10^{\circ}$ to $80^{\circ}$ at $30 \mathrm{kV}$ and $15 \mathrm{~mA}$.

2.5. Spectroscopy. For the synthesized standard and nanopigmented PMMA, Fourier Transform Infra-Red (FTIR) spectroscopy was conducted in a Bruker Vector 33 Instrument, by the transmittance technique. Samples were prepared in $\mathrm{KBr}$ pellets with a weight content of around $1 \%$. Briefly, both resin $(\sim 2 \mathrm{mg})$ and $\mathrm{KBr}(\sim 150 \mathrm{mg})$ were ground together into an agate mortar with an agate pestle until the sample was well dispersed, and the mixture has the consistency of fine flour. Then, a translucent disk was prepared and FTIR spectra were obtained in the wavenumber region between 400 and $4000 \mathrm{~cm}^{-1}$. Specimens were also analyzed by Raman Dispersive Spectroscopy in a Senterra apparatus (Bruker) equipped with $\lambda=685 \mathrm{~nm}$ laser and FT-Raman (Nicolet 910) with $\lambda=1064 \mathrm{~nm}$ in the laser, coupled with an Olympus microscope. The sample was directly deposited onto a holder with no further preparation.

2.6. Scanning Electronic Microscopy. SEM observations were carried out with a JSM-6060LV scanning microscope (JEOL, Peabody, MA). The samples were coated with gold by vacuum evaporation and examined at $\times 100$ magnifications.

2.7. Viscosimetry. Dilute PMMA solutions were made in toluene. The viscosities were measured using an Ubbelohde $1 \mathrm{C}$ capillary viscometer. The test was performed at $25^{\circ} \mathrm{C}$ and the viscosity average molecular weight $(\mathrm{Mv})$ was calculated using the Mark-Houwink-Sakurada equation [12].

2.8. Flexural Behavior. Flexural strength $(S)$ and flexural modulus $(E)$ were measured in a tensile-compression cell (Mecmesin, Horsham, England), using a cross head of $0.5 \mathrm{~kg} / \mathrm{min}$. Specimens $(n=10)$ were loaded to failure in three-point bending. The parameters were calculated from the following [13]:

$$
S=\frac{3 P L}{2 b h^{2}}, \quad E=\frac{F L^{3}}{4 \delta b h^{3}},
$$

where $P$ is the load at break, $b$ and $h$ are the width and the thickness of the specimen, respectively, $L$ is the length between supports $(10 \mathrm{~mm}), \delta$ is the maximum deflection of the center of the beam, and $F$ is the slope of the tangent to the initial straight-line portion of the load-deflection curve. 
2.9. Porosity Test. Samples $(n=10)$ were initially weighted and placed in a silica gel desiccator. Every $24 \mathrm{~h}$ sample weight was recorded until constant weight was reached $( \pm 0.0005 \mathrm{~g})$. Internal porosity (Vip) of each sample was calculated through the equation $\mathrm{Wa}=(\mathrm{dr}-\mathrm{da})(\mathrm{Vsp}-\mathrm{Vip})$, where $\mathrm{Wa}$ is the sample weight $(\mathrm{g}), \mathrm{dr}$ is the acrylic resin density $\left(1.198 \mathrm{~g} / \mathrm{cm}^{3}\right)$, da $\left(0.00123 \mathrm{~g} / \mathrm{cm}^{3}\right)$ is the local air density at $21^{\circ} \mathrm{C}$ and $585 \mathrm{mmHg}$, Vsp is volume of samples, and Vip is the volume of internal porosity $\left(\mathrm{cm}^{3}\right)$ [14].

2.10. Water Sorption and Solubility Test. The discs $(n=10)$ were weighted $(\mathrm{mg})$ and placed in a silica gel dessicator, every $24 \mathrm{~h}$ the discs were weighted until constant mass $\left(m_{1}\right)$. Discs were placed in distilled water for 7 days at $37 \pm 1^{\circ} \mathrm{C}$. After that, the discs were dried and weighted $\left(m_{2}\right)$. The discs were placed in the dessicator again and weighted every $24 \mathrm{~h}$ until constant mass $\left(m_{3}\right)$. Area $(A)$ of each sample was calculated in $\mathrm{cm}^{2}$. Water sorption (Ws) and Solubillity $(\mathrm{Sl})$ were calculated as follows [15]: Ws $=\left(m_{2}-m_{1}\right) / A ; \mathrm{Sl}=\left(m_{1}-m_{3}\right) / A$.

2.11. Toxicity Assay. Specimens from standard and nanoparticles-pigmented PMMA resins were prepared and sterilized by exposure of both faces to ultraviolet irradiation during 5 min. Biocompatibility was assessed by an in vitro test performed in cultured cells in the presence of the new materials $[8,16,17]$. Briefly, NIH-3T3 mouse embryonic fibroblast-like cells were exposed to PMMA specimens, and proliferation was assessed measuring reductase enzymatic activity by transformation of 3-(4,5-dimethylthiazol-2-yl)2,5-diphenyltetrazolium bromide (MTT) into a colored reduced form [18]. Cells were maintained in Dulbecco's Modified Eagle Medium (DMEM) (Gibco, Invitrogen, Carlsbad, CA) supplemented with $10 \%$ fetal bovine serum (Gibco) and $100 \mathrm{U} / \mathrm{mL}$ penicillin-streptomycin at $37^{\circ} \mathrm{C}$ in $5 \% \mathrm{CO}_{2}, 95 \%$ humidity. Cells were plated into 24 -well sterile plates (Nunc-Thermo Fisher Scientific, Roskilde, Denmark) at a concentration of $10^{4}$ cells per well and incubated in $500 \mu \mathrm{L}$ culture medium for $24 \mathrm{~h}$ and $72 \mathrm{~h}$. Then, the culture medium was renewed and specimens were carefully deposited in direct contact to NIH-3T3 cell monolayer. After incubation times, resins were removed, MTT assay was performed following the manufacturer instructions (Sigma, St. Louis, MO), and absorbance was measured in a microplate reader (Bio-Rad 680) at a wavelength of $655 \mathrm{~nm}$. Cell cultures with medium only were used as controls. Each experiment was performed by triplicate.

\subsection{Candida albicans Adhesion Test. Candida albicans strain} 90026 (American Type Culture Collection, Manassas, VA) was cultured overnight in yeast broth (Sigma-Aldrich). Cells were harvested by centrifugation at $3,000 \mathrm{rpm}$ for $5 \mathrm{~min}$, and pellet was adjusted to obtain a suspension with 0.15 optical density at $540 \mathrm{~nm}$. Sterilized resin specimens were placed into 24-well sterile culture plates (Nunc) and $500 \mu \mathrm{L}$ yeast suspension was added. After a 24 -h incubation period at $37^{\circ} \mathrm{C}$, nonadherent cells were removed from specimens by washing for $10 \mathrm{~min}$ under sonication, followed by 3 washings with distilled water for $1 \mathrm{~min}$ under shaking.
Adherent fungi were extracted by incubation with $1.0 \mathrm{~mL}$ benzalconium chloride for $15 \mathrm{~min}$. Finally, a microbial cell viability assay based on luminescent ATP measurement (Bac Titer-Glo, Promega, Fitchburg, WI) was performed in order to determine the number of viable cells adhered to composite resins. Briefly, extract aliquots $(20 \mu \mathrm{L}$ each $)$ were mixed with $30 \mu \mathrm{L}$ BacTiter Glo reagent in $1.5 \mathrm{~mL}$-Eppendorf clear tubes and luminescence was recorded after $5 \mathrm{~min}$ in a 20/20 luminometer (Turner Biosystems, Promega) at wavelength of $590 \mathrm{~nm}$ emission. Relative luminescence intensity, in $10 \mathrm{sec}-$ integration periods, was measured in three samples.

2.13. Statistical Analysis. One-way ANOVA and Tukey test $(P<.05)$ were carried out for the following tests: elastic modulus, transverse strength, porosity, sorption water, solubility, citotoxicity assay, and Candida albicans adhesion.

\section{Results and Discussion}

3.1. Characterization of Metal-Oxide Particles. As observed in Figure 1, metal oxide particles range from 150 to $350 \mathrm{~nm}$ in diameter, showing a normal size distribution. Average size of pigments was found to be $225.9 \mathrm{~nm}$ for $\mathrm{TiO}_{2}$ and $299.7 \mathrm{~nm}$ for $\mathrm{Fe}_{2} \mathrm{O}_{3}$ particles. The pigments were also characterized by $\mathrm{X}$-ray diffraction (XRD) in order to search whether specific crystal phases with antimicrobial properties are present in the powders. The XRD patterns of nanoparticles are shown in Figure 2. Diffractograms indicate crystalline structures for both nanomaterials. Rutile was found to be the major phase in the $\mathrm{TiO}_{2}$ sample, although a certain amount of anatase morphology was also observed (Figure 2(a)). For their part, ferrite particles were found with the hematite crystalline structure (Figure 2(b)).

\subsection{Production and Morphology of Standard and Nanopig-} mented Resins. Synthesis of PMMA was conducted by adding $\mathrm{TiO}_{2}$ and $\mathrm{Fe}_{2} \mathrm{O}_{3}$ nanoparticles during the polymerization step, giving rise to pigmented resins. Standard formulations lacking nanoparticles were prepared and used as controls. SEM analyses showed that synthesis procedures reveal acrylic resins with homogeneous size distribution and morphology for both standard and hybrid materials. SEM micrographs showed the presence of regular spherical particles, with size distributions around $60 \mu \mathrm{m}$ in diameter (Figure 3). The homogeneous distribution of particles suggests that sodium alginate is a suitable suspension agent promoting the formation of spherical PMMA particles, as it has been observed previously [12].

3.3. Spectroscopy. Standard and nanopigmented PMMA were analyzed by FTIR and Raman dispersive spectroscopy. As seen in Figure 4(a), the FTIR spectra show the main expected bands characterizing the vibrational spectrum of PMMA $[19,20]$, namely, the characteristic methylene C-H stretches bands at $2949 \mathrm{~cm}^{-1}$ and the ester carbonyl C=O stretching vibrations at $1722 \mathrm{~cm}^{-1}$. The $\mathrm{C}-\mathrm{O}$ deformation at $1166 \mathrm{~cm}^{-1}$, the $\mathrm{C}-\mathrm{O}-\mathrm{C}$ vibration at $1141 \mathrm{~cm}^{-1}$ and $\mathrm{CH}_{2}$ aromatic group at the band $1437 \mathrm{~cm}^{-1}$. In Figure 4(b), 


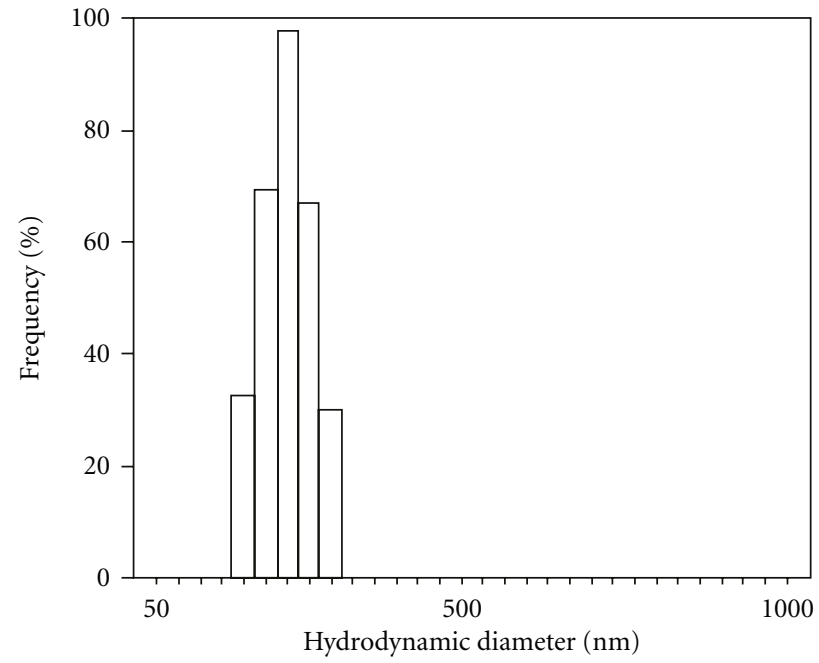

(a)

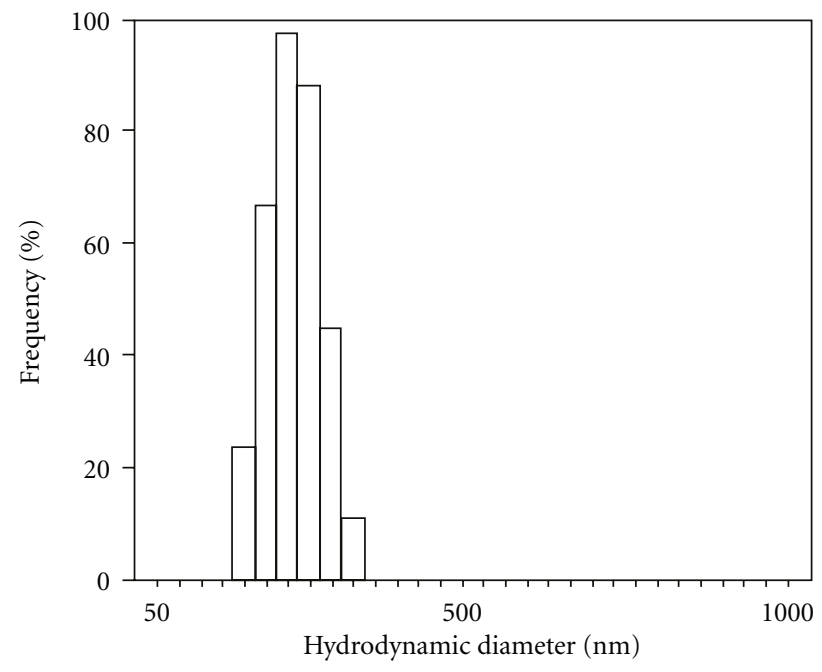

(b)

FIGURE 1: Characterization of metal oxide powders used for pigmented PMMA. Dynamic Light Scattering (DLS) was performed to determine the size distribution of $\mathrm{TiO}_{2}$ (a) and $\mathrm{Fe}_{2} \mathrm{O}_{3}$ (b) nanopigments.

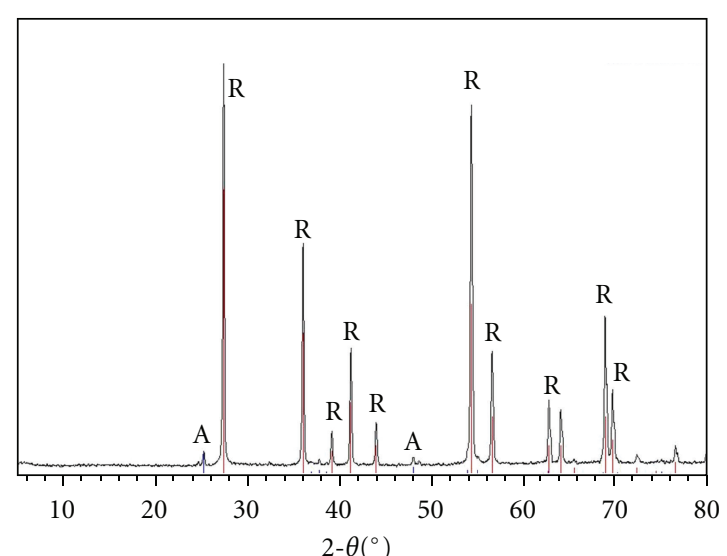

Titania powder R: $\mathrm{TiO}_{2}$ (rutile) A: $\mathrm{TiO}_{2}$ (anatase)

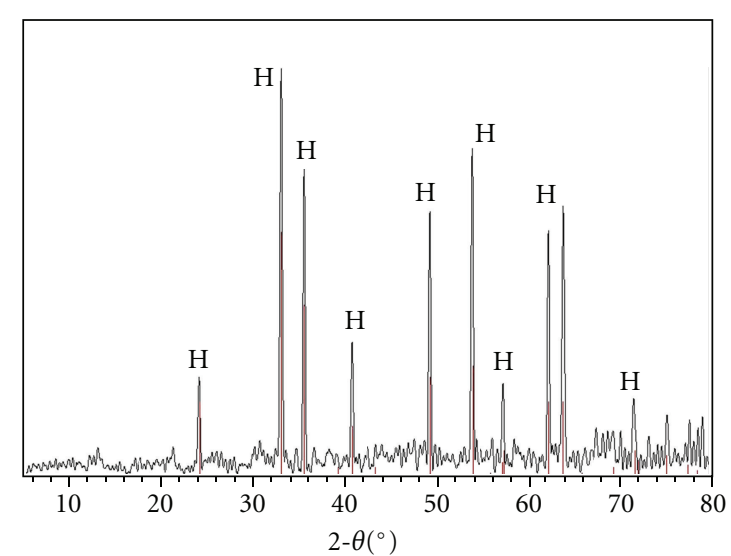

$\mathrm{Fe}_{2} \mathrm{O}_{3}$ powder $\mathrm{H}: \mathrm{Fe}_{2} \mathrm{O}_{3}$ (hematite)

(a)

(b)

Figure 2: X-ray diffraction patterns of $\mathrm{TiO}_{2}$ (a) and $\mathrm{Fe}_{2} \mathrm{O}_{3}$ (b) nanoparticles used in this study. Titania spectrum shows a predominant rutile crystalline structure whereas a hematite phase was found for ferrite.

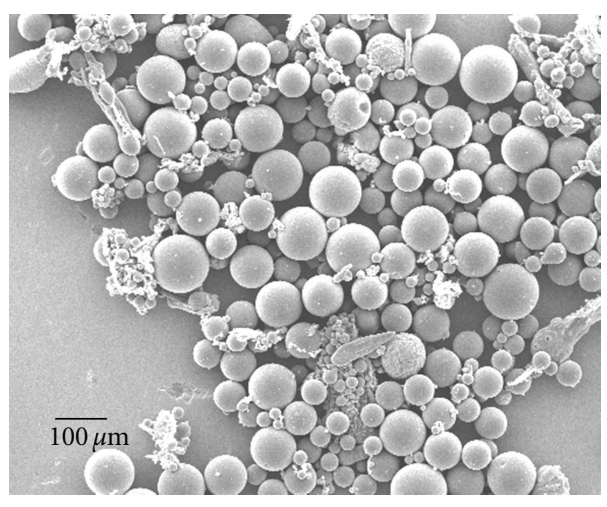

(a)

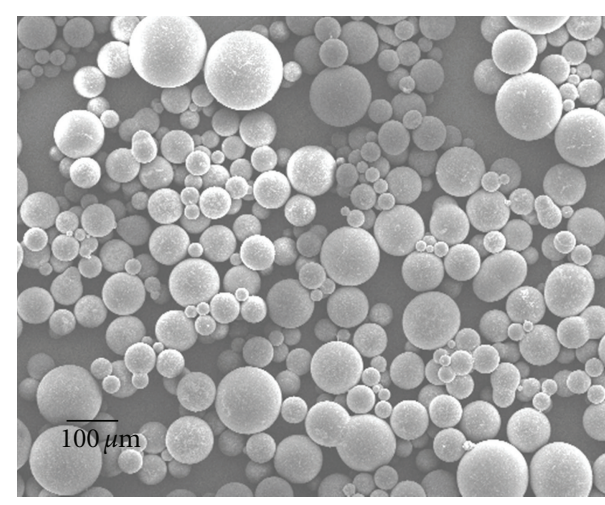

(b)

FIGURE 3: SEM micrograph of standard (a) and nanopigmented PMMA (b) at $\times 100$ magnification. 


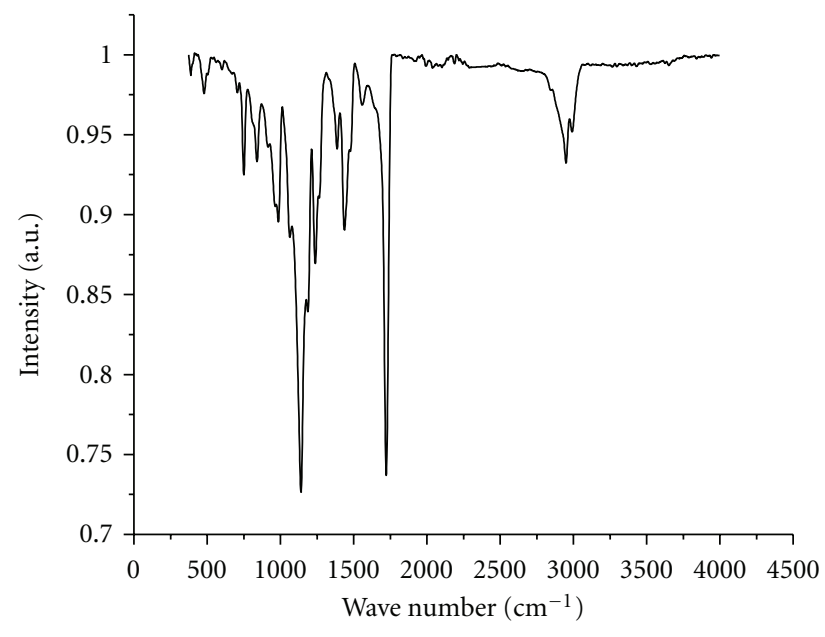

(a)

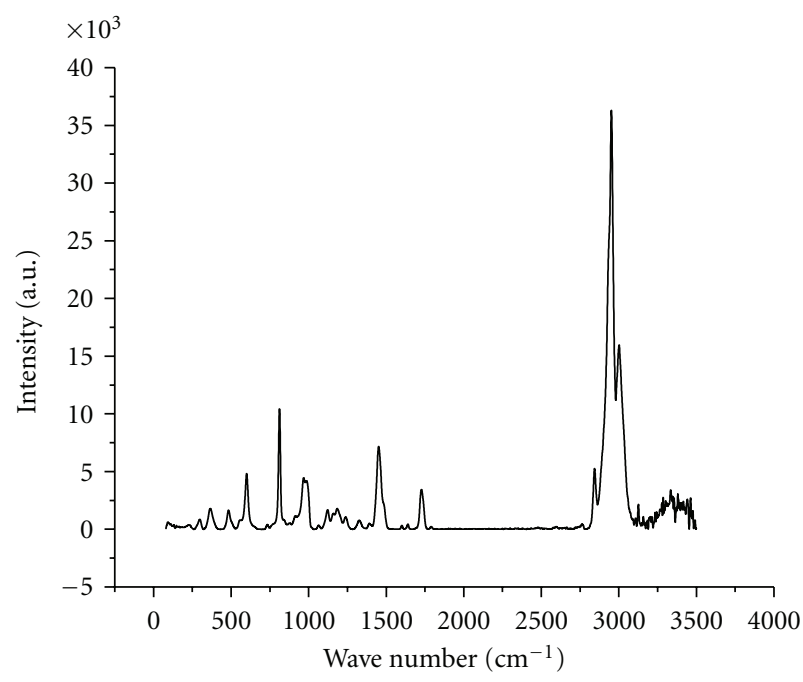

(c)

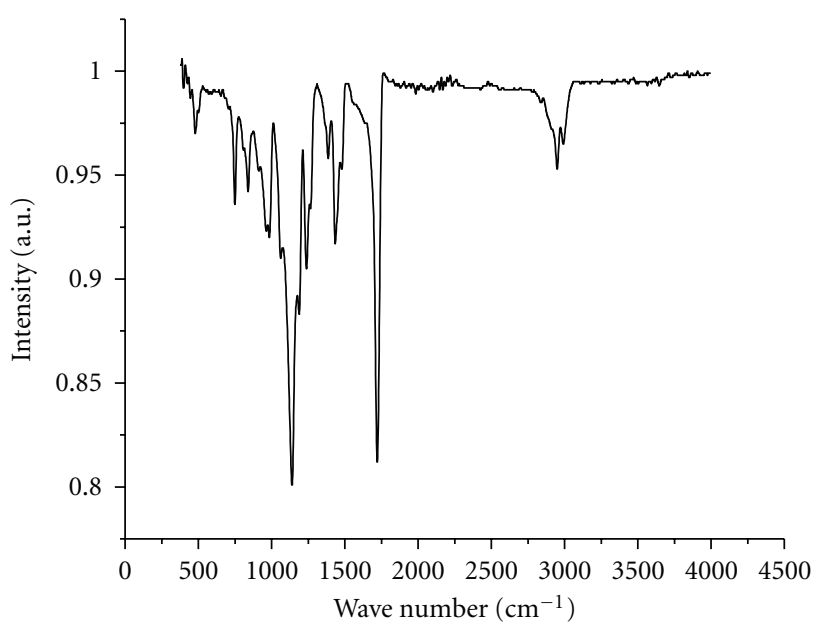

(b)

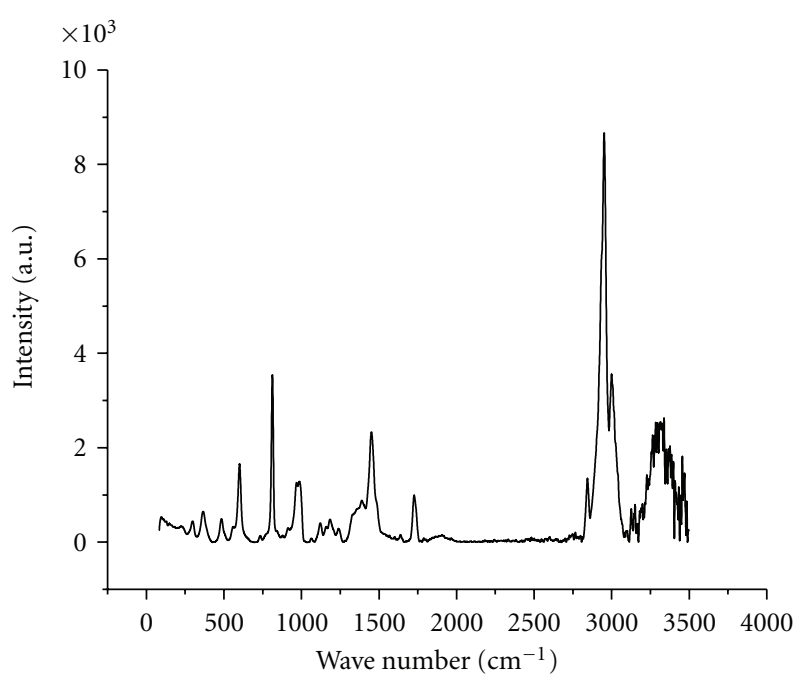

(d)

FIgure 4: Spectroscopy analysis of PMMA resins. (a) FT-IR of standard PMMA. (b) FT-IR of nanopigmented PMMA. (c) and (d) Raman Dispersive spectra from synthesized PMMA resins without and with nanopigments, respectively. Intensity of peaks is in arbitrary units (a.u.).

the vibrational band observed between 2858 and $2958 \mathrm{~cm}^{-1}$ refers to the stretching $\mathrm{C}-\mathrm{H}$ from alkyl groups and the peak between $1722 \mathrm{~cm}^{-1}$ are due to the stretching $\mathrm{C}-\mathrm{O}$ and $\mathrm{C}-\mathrm{O}$ from acetate group remaining from PMMA polymerization. The addition of the nanomaterials did not affect the structure of the original PMMA, but they have helped to substantially improve its properties [21].

A typical sequence of Raman spectra is depicted in Figures 4(c) and 4(d), for the samples: standard and pigmented PMMA, respectively. Bands at 1726, 994, and $812 \mathrm{~cm}^{-1}$ correspond to the carbonyl group of the PMMA polymer [22]. The 601 and $385 \mathrm{~cm}^{-1}$ bands correspond to the nanopigment materials.

3.4. Molecular Weight. The synthesized polymers were subjected to viscometry testing using toluene as solvent. Figure 5 shows the values obtained with the concentration and reduced viscosity of each polymer tested in order to obtain the $y$ value of the graph equation. The $y$ value was replaced in the Mark-Howink-Sakurada equation to get the molecular weight $(\mathrm{Mv})$ of each PMMA. The obtained values of the molecular weight distribution were 24 and $36 \times 10^{5} \mathrm{~g} / \mathrm{mol}$ for the standard PMMA and nanopigmented PMMA, respectively, which probably attributable to the interaction of metal oxides with organic compounds during the synthesis of polymers.

3.5. Flexural Behavior and Porosity. Important physical properties of acrylic resins may be influenced by the presence of $\mathrm{TiO}_{2}$ and $\mathrm{Fe}_{2} \mathrm{O}_{3}$ nanoparticles. In this work, the flexural modulus, flexural strength, and porosity of standard and nanopigmented polymer resins were determined $[23,24]$. As observed in Table 1, flexural behavior was unchanged between standard and nanopigmented PMMA. There was no statistically significant difference in the elastic modulus values $(P>.05)$. In contrast, the transverse strength and 


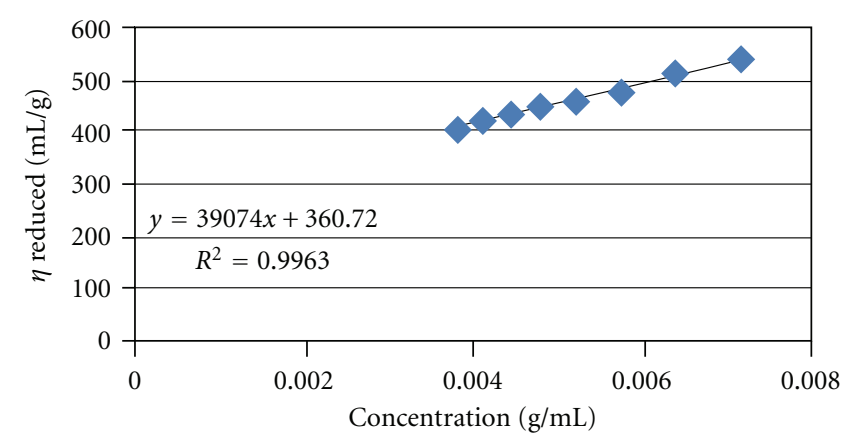

(a)

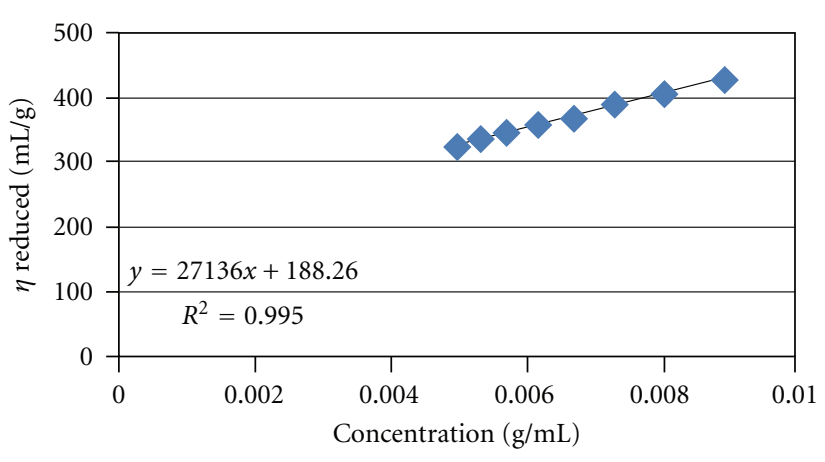

(b)

FIGURE 5: Determination of molecular weight distribution values for standard (a) and nanopigmented (b) PMMA, based on concentration and reduced viscosity analysis.

TABLE 1: Mechanical properties in synthesized standard and nanoparticles-containing PMMA resins.

\begin{tabular}{lccc}
\hline & $\begin{array}{c}\text { Flexural } \\
\text { Modulus }(\mathrm{GPa})\end{array}$ & $\begin{array}{c}\text { Flexural } \\
\text { Strength }(\mathrm{MPa})\end{array}$ & $\begin{array}{c}\text { Porosity } \\
(\%)\end{array}$ \\
\hline $\begin{array}{l}\text { Standard } \\
\text { PMMA }\end{array}$ & $2.5 \pm 0.3$ & $62.3 \pm 4.9$ & $10.5 \pm 0.7$ \\
$\begin{array}{l}\text { Nanopigmented } \\
\text { PMMA }\end{array}$ & $2.5 \pm 1.4$ & $77.6 \pm 5.1$ & $4.6 \pm 0.4$ \\
\hline
\end{tabular}

TABLE 2: Mean values and standard deviation of water sorption and solubility tests from standard and nanopigmented PMMA.

\begin{tabular}{lcc}
\hline & $\begin{array}{c}\text { Water Sorption } \\
\left(\mathrm{mg} / \mathrm{cm}^{2}\right)\end{array}$ & $\begin{array}{c}\text { Solubility } \\
\left(\mathrm{mg} / \mathrm{cm}^{2}\right)\end{array}$ \\
\hline Standard PMMA & $0.71 \pm 0.5$ & $0.041 \pm 0.07$ \\
Nanopigmented PMMA & $0.27 \pm 0.2$ & $0.035 \pm 0.03$ \\
\hline
\end{tabular}

porosity values were found significantly different between standard and nanopigmented resins $(P<.05)$. Flexural values are important in dental prosthetics because biting and mastication forces have a deforming effect during function, and any factor that increases the deformation of the base and changes the stress distribution may lead to denture fracture [2]. In contrast, a strong reduction of porosity was found with the introduction of nanosized metal oxide pigments. It has been reported that significant porosity can severely weaken acrylic resin prosthesis. Regarding hygiene, a denture must be nonporous in order to resist staining, calculus deposition, and adherent substances. A spongy denture tissue surface, full of nutritive substances, is an ideal incubator for species such as Candida albicans.

3.6. Water Sorption and Solubility Test. In a denture base material, water absorbed acts as a plasticizer and affects the dimensional stability, subjecting the material to internal stresses and possible crack formation [25, 26]. Water sorption of PMMA formulations was thus evaluated. Table 2 shows water sorption found in PMMA formulations. Nanopigmented PMMA presented lower sorption value than the standard PMMA. In solubility tests, both polymers showed similar behavior. There was a statistically signifficant difference $(P<.05)$ between groups in water sorption tests. When solubility of polymers was tested (Table 2), no differences were found between formulations, which showed low solubility. These results fulfill with the fact that polymer networks should be insoluble materials, so that chemical and physical processes with deleterious effects on the structure and function of dental polymers can be avoided [25].

3.7. Microbial Adhesion and Cellular Compatibility. Interactions between microbes and surface materials for prosthodontics may result in plaque formation and oral colonization by opportunistic pathogens. The first interactions leading to plaque formation is microbial adherence to surface materials. Herein we performed microbial tests to assess the attachment of Candida albicans, the most common oral-associated pathogen, onto standard and nanoparticlescontaining PMMA. C. albicans was cultured under aerobic conditions to obtain a cell suspension and incubated with specimen disks. After removal of nonadherent fungi, a luminometric assay was performed to estimate adhesion on the new material. As shown in Table 3, PMMA containing nanoparticles showed a lowered $C$. albicans adhesion. Since the antifungal effect may be related to a wide spectrum of cellular toxicity, the activity of fibroblast-like cells cultured in the presence of standard and nanoparticles-containing materials was explored. An enzyme metabolic assay, reflecting viability of cultured cells, showed that nanoparticle-dopped materials have a biocompatibility behavior similar to that of the control group, with no significant differences according to one-way ANOVA test (Figure 6). These results demonstrate that nanostructured metal coloring additives are a suitable means for producing nontoxic hybrid materials with antimicrobial properties for dentistry applications.

\section{Conclusion}

In this study, nanosized $\mathrm{TiO}_{2}$ and $\mathrm{Fe}_{2} \mathrm{O}_{3}$ particles were employed during synthesis of PMMA. In recent years, metal oxide nanoparticles have been largely investigated for their activity as antimicrobial additives. In particular, 
TABle 3: Luminiscence assay results of adherent Candida albicans onto nonpigmented and nanoparticles-pigmented PMMA.

\begin{tabular}{lc}
\hline Acrylic resin & Luminiscence relative units (LRU) \\
\hline Standard PMMA & $25912 \pm 12778$ \\
Nanopigmented PMMA & $23447 \pm 2161$ \\
\hline
\end{tabular}

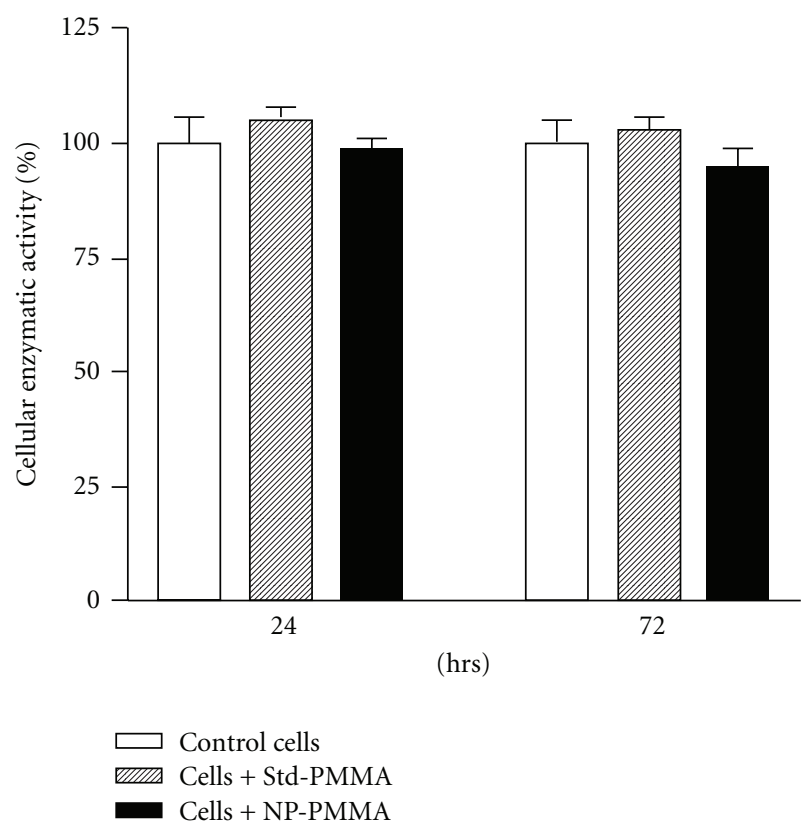

FIGURE 6: Biocompatibility of nonpigmented, standard PMMA (Std-PMMA) and $\mathrm{TiO}_{2} / \mathrm{Fe}_{2} \mathrm{O}_{3}$-containing PMMA (NP-PMMA) as assessed through a metabolic assay in NIH-3T3 fibroblast-like cell line cultures. Cells were exposed to PMMA formulations during 24 or $72 \mathrm{~h}$. No significant differences were found between groups, according to one-way ANOVA test $(P<.05)$.

$\mathrm{TiO}_{2}$ is now considered a low-cost, clean photocatalyst with chemical stability and nontoxicity [27, 28] and has been used for a wide variety of environmental applications, including water treatment [9] and air purification [10, 29]. Herein we report that the introduction of nanosized metal oxide materials for preparing acrylic resins allows the production of polymer with both color and surface modifications. Interestingly, physical tests of nanopigmented and standard PMMA showed a lower porosity for $\mathrm{TiO}_{2} / \mathrm{Fe}_{2} \mathrm{O}_{3}$ containing PMMA. This finding suggests that metal oxide nanoparticles are suitable additives for the improvement of PMMA formulations, since high porosities have been considered a critical drawback for PMMA in prosthodontics applications [30]. Moreover, the nanotechnology-assisted design allows a product with well controlled morphology, as assessed by SEM. Physicomechanical testing also showed that nanoparticles-containing PMMA behave as is specified by the International Standards for Denture Prosthetics $[13,15]$. Since photocatalytic events induced by $\mathrm{TiO}_{2}$ and ferrite nanoparticles may be a source of cellular toxicity, the hybrid pigmented PMMA material was analyzed for biocompatibility, using the MTT assay, an in vitro cellular activity test widely used for dental materials [16, 17]. As shown in Figure 6, cells incubated for different periods with $\mathrm{TiO}_{2} / \mathrm{Fe}_{2} \mathrm{O}_{3}$ containing PMMA indicated that the new formulation was devoid of toxicity. Antimicrobial properties in PMMA formulations were assessed by a luminometry assay of adherent Candida albicans viable cells. The results showed that using the nanoparticles-containing formulation, antimicrobial properties were increased in a slight manner only. Further research must thus include $\mathrm{TiO}_{2}$ mainly composed by particles with anatase crystal structure, a morphology phase corresponding to the highest titania antimicrobial effects [11]. As it was shown by X-ray diffraction analyses, morphology of $\mathrm{TiO}_{2}$ nanoparticles obtained for this study had a low anatase phase amount. Besides, the influence on PMMA properties of nanoparticles concentration remains an important issue to be adressed. In summary, this work points out a potential of metal oxide nanoparticles for the improvement of resin-based dental materials. Further research on the hybrid material is therefore encouraged for future prosthodontics developments.

\section{Acknowledgments}

The authors wish to thank Susana Vargas, Alicia del Real, and Carmen Vázquez for excellent technical assistance. Laura S. Acosta-Torres is recipient of a postdoctoral fellowship from DGAPA/UNAM.

\section{References}

[1] M. Tanoğlu and Y. Ergün, "Porous nanocomposites prepared from layered clay and PMMA [poly(methyl methacrylate)]," Composites Part A: Applied Science and Manufacturing, vol. 38, no. 2, pp. 318-322, 2007.

[2] O. Gurbuz, F. Unalan, and I. Dikbas, "Comparison of the transverse strength of six acrylic denture resins," OHDMBSC, vol. 9, pp. 21-24, 2010.

[3] M. Yamauchi, K. Yamamoto, M. Wakabayashi, and J. Kawano, "In vitro adherence of microorganisms to denture base resin with different surface texture," Dental Materials Journal, vol. 9, no. 1, pp. 19-24, 1990.

[4] S. Hahnel, M. Rosentritt, G. Handel, and R. Bürgers, "In vitro evaluation of artificial ageing on surface properties and early Candida albicans adhesion to prosthetic resins," Journal of Materials Science: Materials in Medicine, vol. 20, no. 1, pp. 249$255,2009$.

[5] J. M. Saunus, A. Kazoullis, and C. S. Farah, "Cellular and molecular mechanisms of resistance to oral Candida albicans infections," Frontiers in Bioscience, vol. 13, pp. 5345-5358, 2008.

[6] L. Kodjikian, C. Burillon, C. Roques et al., "Intraocular lenses, bacterial adhesion and endophthalmitis prevention: a review," Bio-Medical Materials and Engineering, vol. 14, no. 4, pp. 395409, 2004.

[7] M. Shi, J. D. Kretlow, A. Nguyen et al., "Antibiotic-releasing porous polymethylmethacrylate constructs for osseous space maintenance and infection control," Biomaterials, vol. 31, no. 14 , pp. 4146-4156, 2010. 
[8] S. K. Kim, S. J. Heo, J. Y. Koak et al., "A biocompatibility study of a reinforced acrylic-based hybrid denture composite resin with polyhedraloligosilsesquioxane," Journal of Oral Rehabilitation, vol. 34, no. 5, pp. 389-395, 2007.

[9] Q. Li, S. Mahendra, D. Y. Lyon et al., "Antimicrobial nanomaterials for water disinfection and microbial control: potential applications and implications," Water Research, vol. 42, no. 18, pp. 4591-4602, 2008.

[10] L. Sikong, B. Kongreong, D. Kantachote, and W. Sutthisripok, "Photocatalytic activity and antibacterial behavior of $\mathrm{Fe}^{3+}$. doped $\mathrm{TiO}_{2} / \mathrm{SnO}_{2}$ nanoparticles," Energy Research Journal, vol. 1, pp. 120-125, 2010.

[11] C. C. Trapalis, P. Keivanidis, G. Kordas et al., " $\mathrm{TiO}_{2}\left(\mathrm{Fe}^{3+}\right)$ nanostructured thin films with antibacterial properties," Thin Solid Films, vol. 433, no. 1-2, pp. 186-190, 2003.

[12] L. S. Acosta-Torres, F. H. Barceló-Santana, C. A. ÁlvarezGayosso, and J. Reyes-Gasga, "Synthesis and characterization of poly(methyl methacrylate) polymerized by microwave energy or conventional water bath," Journal of Applied Polymer Science, vol. 109, no. 6, pp. 3953-3960, 2008.

[13] ISO 1567, Dentistry-Denture Base Polymers, International Organization for Standardization, Geneva, Switzerland, 1999.

[14] M. A. Compagnoni, D. B. Barbosa, R. F. de Souza, and A. C. Pero, "The effect of polymerization cycles on porosity of microwave-processed denture base resin," Journal of Prosthetic Dentistry, vol. 91, no. 3, pp. 281-285, 2004.

[15] "Revised American Dental Association specification no. 12 for denture base polymers," Journal of the American Dental Association, vol. 90, no. 2, pp. 451-458, 1975.

[16] E. Larraz, C. Elvira, M. Fernández et al., "Self-curing acrylic formulations with applications in intervertebral disk restoration: drug release and biological behaviour," Journal of Tissue Engineering and Regenerative Medicine, vol. 1, no. 2, pp. 120 127, 2007.

[17] G. Meriç, J. E. Dahl, and I. E. Ruyter, "Cytotoxicity of silicaglass fiber reinforced composites," Dental Materials, vol. 24, no. 9, pp. 1201-1206, 2008.

[18] T. Mosmann, "Rapid colorimetric assay for cellular growth and survival: application to proliferation and cytotoxicity assays," Journal of Immunological Methods, vol. 65, no. 1-2, pp. 55-63, 1983.

[19] J. Jiang, "Ultrasonic-assisted synthesis of PMMA/Ni0.5Zn0. $5 \mathrm{Fe} 2 \mathrm{O} 4$ nanocomposite in mixed surfactant system," European Polymer Journal, vol. 43, no. 5, pp. 1724-1728, 2007.

[20] L. H. Sperling, Introduction to Physical Polymer Science, John Wiley \& Sons, New York, NY, USA, 4th edition, 2006.

[21] J. I. Kroschwitz, Polymer: Polymer Characterization and Analysis, John Wiley \& Sons, New York, NY, USA, 1990.

[22] B. Schrader, Infrared and Raman Spectroscopy: Methods and Applications, VCH, 1995.

[23] C. I. Vallo, G. A. Abraham, T. R. Cuadrado, and J. San Román, "Influence of cross-linked PMMA beads on the mechanical behavior of self-curing acrylic cements," Journal of Biomedical Materials Research B, vol. 70, no. 2, pp. 407-416, 2004.

[24] S. Yannikakis, A. Zissis, G. Polyzois, and A. Andreopoulos, "Evaluation of porosity in microwave-processed acrylic resin using a photographic method," Journal of Prosthetic Dentistry, vol. 87, no. 6, pp. 613-619, 2002.

[25] S. H. Tuna, F. Keyf, H. O. Gumus, and C. Uzun, "The evaluation of water sorption/solubility of various acrylic resins," European Journal of Dentistry, vol. 2, pp. 191-197, 2008.
[26] L. D. F. R. Garcia, L. D. M. R. Roselino, F. M. Mundim, F. D. C. P. Pires-de-Souza, and S. Consani, "Influence of artificial accelerated aging on dimensional stability of acrylic resins submitted to different storage protocols," Journal of Prosthodontics, vol. 19, no. 6, pp. 432-437, 2010.

[27] M. R. Hoffmann, S. T. Martin, W. Choi, and D. W. Bahnemann, "Environmental applications of semiconductor photocatalysis," Chemical Reviews, vol. 95, no. 1, pp. 69-96, 1995.

[28] A. Fujishima, T. N. Rao, and D. A. Tryk, "Titanium dioxide photocatalysis," Journal of Photochemistry and Photobiology C: Photochemistry Reviews, vol. 1, no. 1, pp. 1-21, 2000.

[29] T. Nonami, H. Hase, and K. Funakoshi, "Apatite-coated titanium dioxide photocatalyst for air purification," Catalysis Today, vol. 96, no. 3, pp. 113-118, 2004.

[30] A. C. Pero, D. B. Barbosa, J. Marra et al., "Influence of microwave polymerization method and thickness on porosity of acrylic resin," Journal of Prosthodontics, vol. 17, no. 2, pp. 125-129, 2008. 

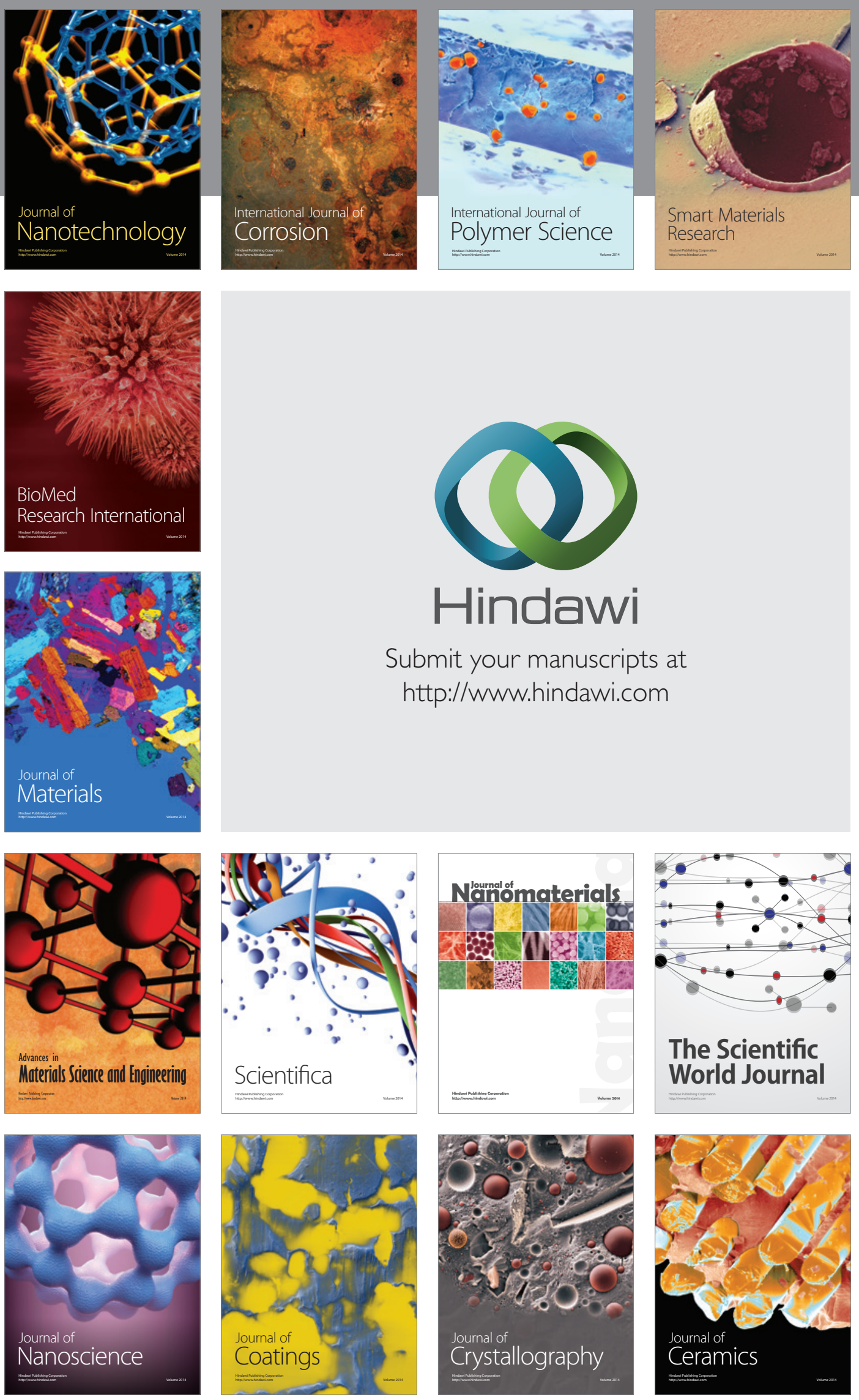

The Scientific World Journal

Submit your manuscripts at

http://www.hindawi.com

\section{World Journal}

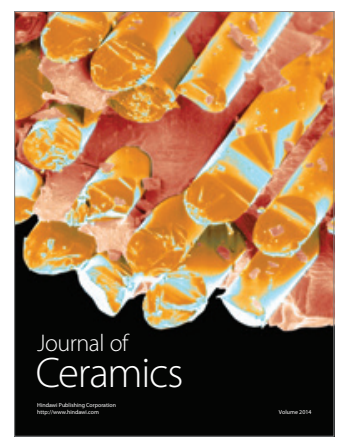

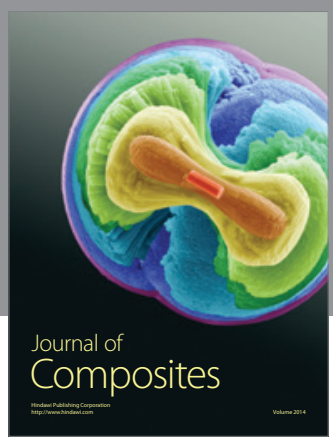
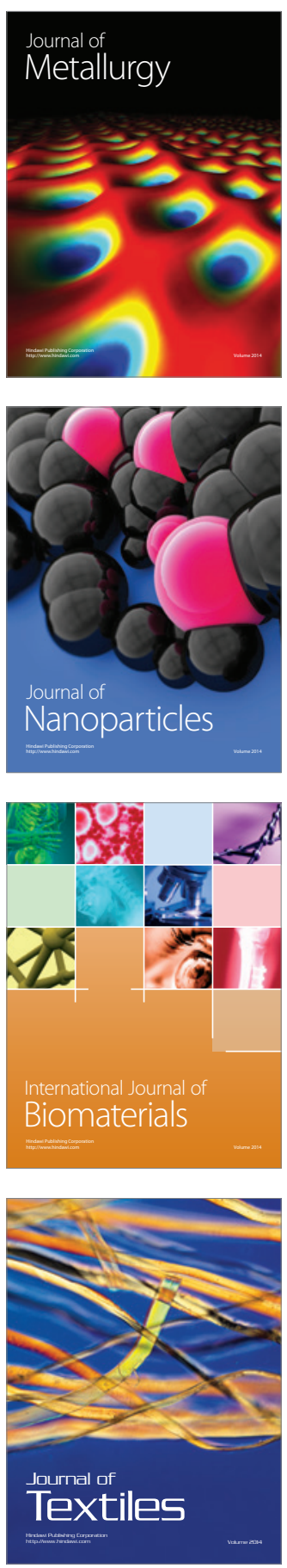